\title{
HPV in non-oropharyngeal head and neck cancer: does it matter?
}

\author{
Nicole C. Schmitt \\ Department of Otolaryngology - Head and Neck Surgery, Winship Cancer Institute, Emory University School of Medicine, Atlanta, GA, USA \\ Correspondence to: Nicole C. Schmitt, MD. Department of Otolaryngology - Head and Neck Surgery, Emory University School of Medicine, 550 \\ Peachtree Street NE, 9th Floor, Atlanta, GA 30308, USA. Email: nicole.cherie.schmitt@emory.edu. \\ Comment on: Zhu Y, Xia X, Gao L, et al. Prognostic implications of human papillomavirus type 16 status in non-oropharyngeal head and neck cancer: \\ a propensity score matching analysis. Ann Transl Med 2019;7:759.
}

Submitted Apr 16, 2020. Accepted for publication Jun 22, 2020.

doi: $10.21037 /$ atm-20-3346

View this article at: http://dx.doi.org/10.21037/atm-20-3346

The incidence of head and neck squamous cell carcinoma (HNSCC) varies across the globe due to the prevalence of different risk factors. Exposure to carcinogens such as tobacco, alcohol and betel nut remain common in some parts of the world, while parts of Africa and Asia have higher incidence of nasopharyngeal carcinoma related to Epstein Barr virus. Over the past two decades, it has become increasingly clear that a subset of HNSCC, primarily in the oropharynx, is driven by human papillomavirus (HPV). It is now well established that HPVdriven oropharyngeal squamous cell carcinoma (OPSCC) is associated with favorable treatment responses and survival outcomes compared with HPV-negative OPSCC (1). However, the significance of HPV detected in head and neck tumors outside of the oropharynx is unclear. The existence of tumors in other anatomic sites that contain transcriptionally-active virus and histologic features of HPV-positive OPSCC (non-keratinizing, endophytic growth) has been reported, suggesting that the oncogenesis of these tumors is truly HPV-driven (2).

Prior studies investigating whether the presence of HPV affects survival outcomes in non-oropharyngeal HNSCC have shown mixed results. Most of these prior studies are not adequately powered to detect a difference in survival, since the proportion of non-oropharyngeal HNSCC specimens harboring evidence of HPV is relatively small. This proportion varies from about $2-39 \%$ depending on the anatomic subsite, with a larger proportion of HPVpositive tumors in the larynx/hypopharynx versus the oral cavity (3-11). As a result of these factors, most singleinstitution studies with a few hundred cases or less have not shown a statistically significant improvement in survival for HPV-positive tumors outside of the oropharynx
$(4-7,9,12,13)$. A few larger studies including several hundred or more patients have shown improved outcomes for HPVdriven tumors, particularly for laryngeal cancers treated with chemoradiation $(3,14-17)$. Interestingly, a few studies have shown that patients with HPV-positive tumors in the oral cavity had worse survival outcomes (18-20). Another important factor to consider is the variable methodology used to detect HPV in these studies. The more stringent studies used both molecular methods to detect HPV DNA and immunohistochemistry to detect p16, a well-validated surrogate marker of HPV; other studies favored one of these methods or accepted either as evidence of HPV-positivity (3). Some of the studies included only HPV 16, the most common high-risk subtype associated with OPSCC, while other studies also included less common subtypes. Importantly, the presence of HPV DNA and p16 are often discordant, especially outside of the oropharynx, where p16 is not necessarily associated with transcriptionally active virus or HPV-driven tumor biology $(21,22)$.

In a recent study published in Annals of Translational Medicine, Zhu and colleagues investigated the relationship between HPV 16 status and survival outcomes in a large cohort of 1,539 patients with non-oropharyngeal HNSCC at a single institution in China (17). In $8.5 \%$ of cases ( $\mathrm{n}=131)$, HPV 16 DNA was detected. In attempt to limit some of the biases inherent to retrospective studies, the authors used propensity score matching (PSM). Though propensity scoring has limitations, it attempts to adjust post-hoc for unbalanced factors among cohorts in order to better approximate what a randomized, controlled trial would show (23). Following PSM, the authors compared diseasespecific and overall survival in patients with HPV-positive versus negative tumors in the larynx, hypopharynx, and oral 
cavity. Although survival was clearly not different based on HPV 16 status for patients with tumors in the oral cavity or hypopharynx, those with HPV+ laryngeal cancers had statistically significant improvements in DSS and OS (17). These significant differences were seen for the laryngeal subsite in the entire patient cohort but were more striking in the propensity-adjusted cohort.

Zhu and colleagues did acknowledge that these results from their single-institution study may not necessarily be generalizable to other patient populations (17). A large study from the United States analyzed the effects of HPV status on survival outcomes in cases from the National Cancer Database (NCDB), with similar overall methodology but different results (16). In the NCDB study by Tian et al., non-oropharyngeal cases of HNSCC that were positive for HPV 16, 18, or other high-risk HPV types were compared to HPV-negative cases, again using PSM (16). After excluding cases with insufficient information, a total of 9,907 patients with non-OPSCC were included in the analysis. Cases were further stratified into stage I/II versus III/IV, except for the hypopharynx due to lower cases numbers for that anatomic site. In contrast to the study by Zhu et al., survival differences based on HPV status in the NCDB study were more striking in the hypopharynx and oral cavity, whereas the smaller difference in OS for HPVpositive versus negative tumors was not quite statistically significant for the larynx $(\mathrm{P}=0.063)$. While reasons for this major difference in results among subsites between the Zhu et al. and Tian $e t a l$. studies are not entirely clear, they are likely related in part to different patient populations from two different continents, with variable rates of other genetic and environmental risk factors. Tian and colleagues also acknowledged that major limitations are present when using a cancer database, including a lack of information on how HPV testing was performed (16). Though Zhu et al. only included HPV 16 (17), their detection methods were uniform.

For OPSCC, information on HPV status is critical for patient counseling and enrollment in clinical trials of deescalated therapy, since the majority of oropharyngeal tumors are HPV-related with a favorable prognosis. Currently, testing for HPV is rarely performed on nonoropharyngeal HNSCC tumors due to the lack of information on how this information can be used in clinical practice. Data on how HPV-driven tumors outside the oropharynx respond to different modalities of therapy are lacking, and the possibility of prognostic information in the minority of HPV-driven cases is not sufficiently motivating for routine testing of all non-OPSCCs.
In summary, large, prospective studies investigating HPV status in non-oropharyngeal HNSCC are lacking, and retrospective studies showed mixed results. These discrepancies may be related to limited sample sizes, different study populations, and varying methods of detecting HPV. Larger studies, including the two discussed above, do suggest that a real survival difference exists for the minority of HPV-driven head and neck tumors arising outside the oropharynx. The prospective studies that would be needed to validate these findings have not yet been a research priority, since the potential effects on treatment options and shared decision making are unclear. As more is learned about equally-effective, less toxic treatment deescalation strategies for HPV-positive OPSCC with its favorable prognosis, it will be important to revisit whether HPV-driven tumors of the larynx, hypopharynx, and oral c may also portend a favorable prognosis with a need for alternative treatment strategies.

\section{Acknowledgments}

Funding: None.

\section{Footnote}

Provenance and Peer Review: This article was commissioned by the editorial office, Annals of Translational Medicine. The article did not undergo external peer review.

Conflicts of Interest: The author has completed the ICMJE uniform disclosure form (available at http://dx.doi. org/10.21037/atm-20-3346). Dr. NCS reports grants from Astex Pharmaceuticals, outside the submitted work.

Ethical Statement: The author is accountable for all aspects of the work in ensuring that questions related to the accuracy or integrity of any part of the work are appropriately investigated and resolved.

Open Access Statement: This is an Open Access article distributed in accordance with the Creative Commons Attribution-NonCommercial-NoDerivs 4.0 International License (CC BY-NC-ND 4.0), which permits the noncommercial replication and distribution of the article with the strict proviso that no changes or edits are made and the original work is properly cited (including links to both the formal publication through the relevant DOI and the license). See: https://creativecommons.org/licenses/by-nc-nd/4.0/. 


\section{References}

1. Fakhry C, Westra WH, Li S, et al. Improved survival of patients with human papillomavirus-positive head and neck squamous cell carcinoma in a prospective clinical trial. J Natl Cancer Inst 2008;100:261-9.

2. Rooper LM, Windon MJ, Hernandez T, et al. HPVpositive Squamous Cell Carcinoma of the Larynx, Oral Cavity, and Hypopharynx: Clinicopathologic Characterization With Recognition of a Novel Warty Variant. Am J Surg Pathol 2020;44:691-702.

3. Chung CH, Zhang Q, Kong CS, et al. p16 protein expression and human papillomavirus status as prognostic biomarkers of nonoropharyngeal head and neck squamous cell carcinoma. J Clin Oncol 2014;32:3930-8.

4. Erkul E, Yilmaz I, Narli G, et al. The presence and prognostic significance of human papillomavirus in squamous cell carcinoma of the larynx. Eur Arch Otorhinolaryngol 2017;274:2921-6.

5. Hughes RT, Beuerlein WJ, O'Neill SS, et al. Human papillomavirus-associated squamous cell carcinoma of the larynx or hypopharynx: Clinical outcomes and implications for laryngeal preservation. Oral Oncol 2019;98:20-7.

6. Salazar CR, Smith RV, Garg MK, et al. Human papillomavirus-associated head and neck squamous cell carcinoma survival: a comparison by tumor site and initial treatment. Head Neck Pathol 2014;8:77-87.

7. Sanchez Barrueco A, Gonzalez Galan F, Villacampa Auba JM, et al. p16 Influence on Laryngeal Squamous Cell Carcinoma Relapse and Survival. Otolaryngol Head Neck Surg 2019;160:1042-7.

8. Shaughnessy JN, Farghaly H, Wilson L, et al. HPV: a factor in organ preservation for locally advanced larynx and hypopharynx cancer? Am J Otolaryngol 2014;35:19-24.

9. Young RJ, Urban D, Angel C, et al. Frequency and prognostic significance of $\mathrm{p} 16$ (INK4A) protein overexpression and transcriptionally active human papillomavirus infection in laryngeal squamous cell carcinoma. Br J Cancer 2015;112:1098-104.

10. Scheel A, Bellile E, McHugh JB, et al. Classification of TP53 mutations and HPV predict survival in advanced larynx cancer. Laryngoscope 2016;126:E292-9.

11. Upile NS, Shaw RJ, Jones TM, et al. Squamous cell carcinoma of the head and neck outside the oropharynx is rarely human papillomavirus related. Laryngoscope 2014;124:2739-44.

12. Sanchez Barrueco A, Gonzalez Galan F, Lora Pablos D, et al. HPV in Larynx Squamous Cell Carcinoma: New
Serotypes and Survival Study within 10-Year Follow-up. Otolaryngol Head Neck Surg 2017;156:677-82.

13. Wendt M, Romanitan M, Nasman A, et al. Presence of human papillomaviruses and p16 expression in hypopharyngeal cancer. Head Neck 2014;36:107-12.

14. Bates JE, Morris CG, Hitchcock KE, et al. Locally advanced hypopharyngeal and laryngeal cancer: Influence of HPV status. Radiother Oncol 2019;140:6-9.

15. Li H, Torabi SJ, Yarbrough WG, et al. Association of Human Papillomavirus Status at Head and Neck Carcinoma Subsites With Overall Survival. JAMA Otolaryngol Head Neck Surg 2018;144:519-25.

16. Tian S, Switchenko JM, Jhaveri J, et al. Survival outcomes by high-risk human papillomavirus status in nonoropharyngeal head and neck squamous cell carcinomas: A propensity-scored analysis of the National Cancer Data Base. Cancer 2019;125:2782-93.

17. Zhu Y, Xia X, Gao L, et al. Prognostic implications of human papillomavirus type 16 status in non-oropharyngeal head and neck cancer: a propensity score matching analysis. Ann Transl Med 2019;7:759.

18. Dediol E, Sabol I, Virag M, et al. HPV prevalence and p16INKa overexpression in non-smoking non-drinking oral cavity cancer patients. Oral Dis 2016;22:517-22.

19. Duray A, Descamps G, Decaestecker C, et al. Human papillomavirus DNA strongly correlates with a poorer prognosis in oral cavity carcinoma. Laryngoscope 2012;122:1558-65.

20. Lee LA, Huang CG, Tsao KC, et al. Human Papillomavirus Infections are Common and Predict Mortality in a Retrospective Cohort Study of Taiwanese Patients With Oral Cavity Cancer. Medicine (Baltimore) 2015;94:e2069.

21. Hernandez BY, Rahman M, Lynch CF, et al. p16(INK4A) expression in invasive laryngeal cancer. Papillomavirus Res 2016;2:52-5.

22. Palve V, Bagwan J, Krishnan NM, et al. Detection of High-Risk Human Papillomavirus in Oral Cavity Squamous Cell Carcinoma Using Multiple Analytes and Their Role in Patient Survival. J Glob Oncol 2018;4:1-33.

23. Reiffel JA. Propensity Score Matching: The 'Devil is in the Details' Where More May Be Hidden than You Know. Am J Med 2020;133:178-81.

Cite this article as: Schmitt NC. HPV in non-oropharyngeal head and neck cancer: does it matter? Ann Transl Med 2020;8(18):1120. doi: 10.21037/atm-20-3346 